\title{
Measurement of Serum Alpha-Fetoprotein in Early Infancy: Utilization of Dried Blood Specimens
}

\author{
GERALD J. MIZEJEWSKI, ${ }^{(43)}$ THOMAS P. CARTER, DIANE W. BEBLOWSKI, AND \\ RONALD BELLISARIO \\ Birth Defects Institute, Center for Laboratories and Research, New York State Department of Health, \\ Albany, New York, USA
}

\begin{abstract}
Summary
Serum alpha-fetoprotein (AFP) concentrations were measured in dried blood spots and the biologic half-life of AFP was determined during the first month after parturition. AFP blood levels, in babies at all birthweight groups during the first wk, were partitioned according to birthweight and sex. A synthetic surge of serum AFP at postnatal day 3 was observed in babies of the low birthweight category ( $<6 \mathrm{lb} 8 \mathrm{oz})$, whereas a concomitant surge could not be demonstrated in babies of medium, $(6 \mathrm{lb} 8 \mathrm{oz}$ to $8 \mathrm{lb}$ $8 \mathrm{oz}$ ), and high birthweight, ( $>8 \mathrm{lb} 8 \mathrm{oz}$ ), categories. All babies weighing less than $6 \mathrm{lb} 8 \mathrm{oz}$, regardless of prematurity likewise displayed the synthetic surge. The sex of the infant appeared to have no influence on AFP serum concentrations. In a population of infants ranging in age from 1-30 days, the biologic apparent half-life of AFP was calculated as 5.7 days; however, the half-life of AFP was found to differ among the three groups of infants when subdivided by birthweight and was higher ( 7.7 days) in babies of low birthweight. Our determination of 2 S.D. cutoff values for AFP in the first wk of life should prompt further studies in which the relationship of AFP to newborn disorders should be more fully explored.
\end{abstract}

In man, the clinical value of alpha-fetoprotein (AFP) in the prenatal detection of open neural tube defects (NTD) and in postoperational tumor monitoring is now well established $(37,40)$. The first reports of the relationship of AFP in amniotic fluid to NTDs was published in 1972 (4); in the following year this observation was extended to include maternal serum (19). Since that time period, several investigations have examined the suitability of AFP as a marker for infant and newborn disease. Reports in the literature, although not always consistent, now indicate that the measurement of AFP blood concentrations may be useful in the detection and/or differentiation of at least 18 newborn and infant disorders and possibly even more. These newborn disorders include ataxia telangiectasia $(30,39)$, hereditary tyrosinemia $(12$, $13)$, Indian childhood cirrhosis $(9,28)$, biliary hypoplasia $(1,42)$, biliary atresia $(36,42)$, hyperbilirubinaemia $(23,31,32)$, Rhisoimmunizations (29), yolk sac tumors (6), testicular carcinoma and hepatoma $(26,35)$, hepatoblastoma (6), prematurity (1), neonatal hepatitis $(9,42)$, physiologic jaundice $(20,34)$, infantile obstructive jaundice (27), choledochal cysts $(27,42)$, and possibly cystic fibrosis $(10,31)$, hypothyroidism (33), and ependymoblastoma (18). Although the diagnostic specificity of AFP detection might appear diminished, the range of identifiable perinatal problems may actually be increased. The relatively high concentrations of alpha-fetoprotein in neonatal blood $(17,41)$, as well as its potential clinical importance, make this fetal protein an exceptional candidate for measurement in newborn dried blood specimens.

Recently, we described the adaptation of commercial radioim- munoassay kits for the quantitative determination of AFP in paper-spotted samples of dried newborn blood (24). The need for a means to measure AFP concentrations in newborn dried blood specimens emerged while attempting to assess the potential use of AFP as a diagnostic aid in a newborn screening program. In the present report, we have determined normal, baseline AFP levels in newborn dried blood specimens from birth to 30 days of age. Data have been presented in light of sex, birthweight, and apparent half-life (1-30 days). We have also determined 2 S.D. cutoff values (partitioned by birthweight) for AFP blood concentrations during the first 7 days of extrauterine life.

\section{MATERIALS AND METHODS}

Specimens. Approximately 800 newborn dried blood specimens, obtained by heel-prick from newborns and applied as 1.3-cm spots onto filter paper (Schleicher and Schuell (\#903)), were employed for this study. Dried blood specimens for use as quality controls were prepared by spotting single drops $(60 \mu \mathrm{l})$ of the newborn blood from a micropipette directly onto the filter paper. The specimens were stored in plastic bags at $40^{\circ} \mathrm{C}$. For use in the assay, paper discs (1/16th inch diameter) were punched from the central region of blood spots directly into $12 \times 75 \mathrm{~mm}$ polystyrene test tubes.

Sample preparation. All dried blood specimens were eluted with buffer before radioimmunoassay (RIA) as previously described (24). One $1 / 16$ th-inch disc spot per sample $(0.75 \mu \mathrm{l}$ of blood) was eluted for $1 \mathrm{~h}$ at room temperature into $100 \mu \mathrm{l}$ of a "zero standard" buffer supplied with the RIA kit (see below). The conversion of AFP $\mu \mathrm{g} /$ liter units obtained by use of the RIA kit into $\mathrm{mg} /$ liter units of actual newborn blood levels was calculated assuming: (a) a hematocrit spot value of 50\%, and (b) a total blood volume of $0.75 \mu \mathrm{l}$ per $1 / 1 \mathrm{~s}$ th-inch dried blood spot.

Assay method and standards. The adaptation and use of commercial RIA kits for the measurement of alpha-fetoprotein in newborn dried blood specimens has already been reported (24). The radioimmunoassay kits of $\left[{ }^{125} \mathrm{I}\right]$-human AFP were purchased from Amersham Corporation (Arlington Heights, IL). After elution, the assay involved the following steps: (1) addition of $\left[{ }^{125} \mathrm{I}\right]-$ AFP $(100 \mu \mathrm{l})$ to each tube and (2) followed by the addition of 100 $\mu l$ of rabbit antibody to human AFP. The tubes were then incubated at room temperature overnight $(18 \mathrm{~h})$ to allow competition of antigen for antibody to proceed. To precipitate the immune complexes, $1000 \mu 1$ of polyethylene glycol was added to each tube. After vortexing, the tubes were centrifuged at $1000 \times g$ for $10 \mathrm{~min}$ at $4^{\circ} \mathrm{C}$. The supernatant was decanted and radioactivity determined in a Beckman GAMMA-4000 (71\% efficiency). The assay variation for liquid samples stated in the Amersham Kit was 7\% (intraassay) and $8 \%$ (interassay) whereas the assay variation for dried blood specimens was $12.2 \%$ and $12.3 \%$, respectively (24).

Half-life determination. The apparent half-life of AFP in indi- 
viduals was determined using infants 1-30 days of age. The term "apparent" signifies that the data was collected from single samples of many individuals rather than multiple sequential samples from the same individuals over a 30 -day period. A semilogarithmic plot was used to demonstrate the rate of decline of AFP in calculating the apparent half-life for AFP as described by Wu et al. (41). The half-life of AFP degradation is the time interval corresponding to a decrease of $\log 2$ of the time at Log AFP concentration at day zero divided by two. Half-life determination follows first-order kinetics and is expressed in days.

\section{RESULTS}

AFP in newborn dried blood spots. The AFP blood concentrations for days 1-7 after birth were plotted after the data were partitioned according to three birthweight categories (Fig. 1). Comparable data on nonpartitioned AFP blood concentrations during this time period have previously been described (24). In our arbitrary classification, the low birthweight groups $(<6 \mathrm{lb} 8$ oz) were clearly distinguishable from the remaining weight groups (Fig. 1). The level of AFP in the low birthweight group increased from day one and peaked at day 3 in contrast to the other two groups. The low birthweight AFP levels then gradually declined to day 6 but failed to attain the AFP levels common to the medium and to high birthweight levels. Although the latter two groups underwent mild fluctuations in AFP concentrations throughout the first wk of life, the two groups were not significantly different. These data may indicate that AFP in low birthweight babies undergoes a synthetic surge on the third day of postnatal life maintaining relatively higher serum AFP levels throughout the first wk: A statistical account of the AFP serum levels during the first wk of life is displayed in Table 1. Values for the mean, S.D., and 2 S.D. cutoff are listed for each of the 7 postnatal days in the three selected weight categories.

Because babies in the low birthweight group $\left(<6 \frac{1}{2} \mathrm{lb}\right)$ displayed a postsynthetic surge of AFP during the first wk of life, further studies were performed to establish whether prematurity (by weight) played a role in these observations. The AFP blood levels in babies weighing less than $6 \frac{1}{2} \mathrm{lb}$ at birth were partitioned into two further categories. As displayed in Table 2 values for the

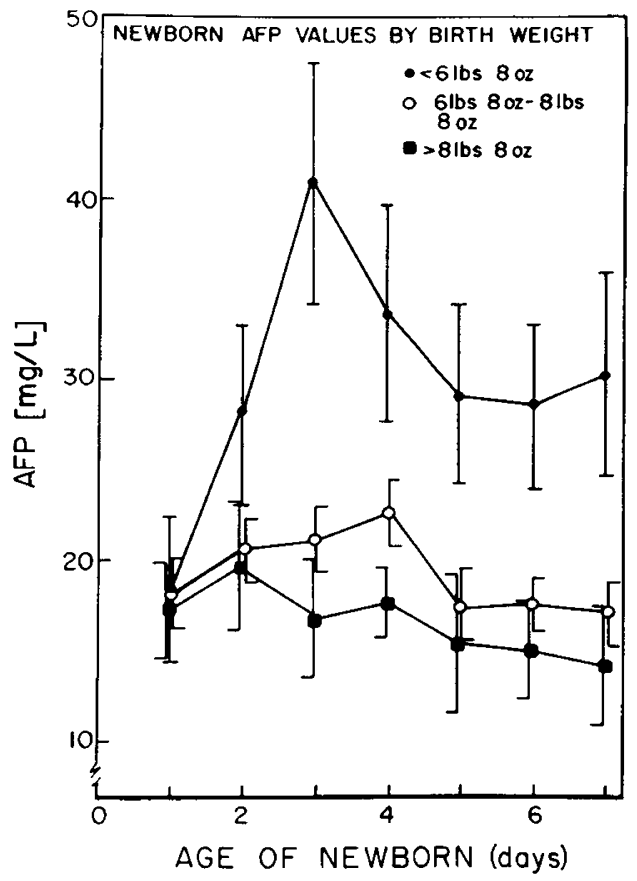

Fig. 1. When the newborn alpha-fetoprotein (AFP) blood concentration data the first wk of life is partitioned according to birth weight, the low birthweight groups $(<6 \mathrm{lb} .8 \mathrm{oz})$ are clearly distinguished from the remaining weight groups. Bars indicate S.E. (S.E.).
Table 1. Statistical parameters of alpha-fetoprotein (AFP) serum levels in 1-7 day newborns partitioned by birth weight

\begin{tabular}{|c|c|c|c|c|c|}
\hline \multirow[b]{2}{*}{ Birth weight } & \multirow[b]{2}{*}{$\begin{array}{l}\text { Age of } \\
\text { infant } \\
\text { (days) }\end{array}$} & \multirow{2}{*}{$\begin{array}{c}\text { Sample } \\
\text { size } \\
(N)\end{array}$} & \multicolumn{3}{|c|}{ AFP (mg/liter) } \\
\hline & & & Mean & S.D.' & $\begin{array}{c}\text { Mean } \\
+2 \text { S.D. }\end{array}$ \\
\hline Low & 1 & 15 & 18.39 & 15.37 & 49.13 \\
\hline \multirow[t]{6}{*}{$(<6 \mathrm{lb} 8 \mathrm{oz})$} & 2 & 18 & 28.24 & 21.14 & 70.52 \\
\hline & 3 & 20 & 41.00 & 30.73 & 102.46 \\
\hline & 4 & 20 & 33.58 & 26.64 & 86.86 \\
\hline & 5 & 20 & 29.08 & 21.99 & 73.06 \\
\hline & 6 & 20 & 28.50 & 20.74 & 69.98 \\
\hline & 7 & 20 & 30.15 & 24.50 & 79.15 \\
\hline Medium & 1 & 64 & 18.20 & 15.74 & 49.68 \\
\hline \multirow[t]{6}{*}{$(6 \mathrm{lb} 8 \mathrm{oz}-8 \mathrm{lb} 8 \mathrm{oz})$} & 2 & 72 & 20.78 & 14.95 & 50.68 \\
\hline & 3 & 72 & 21.20 & 15.60 & 52.40 \\
\hline & 4 & 70 & 22.46 & 14.94 & 52.34 \\
\hline & 5 & 65 & 17.54 & 16.76 & 51.06 \\
\hline & 6 & 73 & 17.72 & 12.69 & 43.10 \\
\hline & 7 & 63 & 17.14 & 14.37 & 45.88 \\
\hline High & 1 & 14 & 17.23 & 10.07 & 37.37 \\
\hline \multirow[t]{6}{*}{$(>8 \mathrm{lb} 8 \mathrm{oz})$} & 2 & 19 & 19.64 & 15.32 & 50.28 \\
\hline & 3 & 20 & 16.74 & 14.90 & 46.54 \\
\hline & 4 & 20 & 17.64 & 8.43 & 34.50 \\
\hline & 5 & 20 & 15.33 & 18.08 & 51.49 \\
\hline & 6 & 20 & 14.90 & 12.90 & 40.70 \\
\hline & 7 & 20 & 14.0 & 14.58 & 43.20 \\
\hline
\end{tabular}

${ }^{1}$ S.D., standard deviation.

Table 2. The concentration of alpha-fetoprotein $(A F P)$ is presented for newborns during the first wk of life. Data is partitioned into various low birth weight categories

\begin{tabular}{ccccccc}
\hline & \multirow{2}{*}{$\begin{array}{c}\text { Age of } \\
\text { infant }\end{array}$} & $\begin{array}{c}\text { Sample } \\
\text { size }\end{array}$ & \multicolumn{2}{c}{ AFP (mg/liter) } & \\
\cline { 5 - 6 } Birth weight & (days) & $(N)$ & Mean & S.D. ${ }^{1}$ & S.E. $^{2}$ & Mean \\
+ 2 S.D. \\
\hline (5 lb 8 oz-6 lb 8 & 1 & 11 & 20.25 & 17.52 & 5.27 & 55.29 \\
oz) & 2 & 16 & 31.48 & 20.32 & 5.08 & 72.12 \\
& 3 & 17 & 40.94 & 30.74 & 7.46 & 102.42 \\
& 4 & 17 & 43.12 & 25.84 & 6.27 & 85.81 \\
& 5 & 23 & 24.11 & 11.60 & 2.42 & 47.31 \\
& 6 & 15 & 28.90 & 21.89 & 5.66 & 72.68 \\
Premature (SGA) & 7 & 14 & 27.31 & 26.74 & 7.15 & 80.79 \\
(<5 lb 8 oz) & 1 & 3 & 15.57 & 4.02 & 2.32 & 23.61 \\
& 2 & 3 & 12.80 & 15.62 & 9.03 & 44.04 \\
& 3 & 15 & 37.60 & 29.61 & 7.65 & 96.82 \\
& 4 & 25 & 28.70 & 19.78 & 9.89 & 68.26 \\
& 5 & 9 & 35.20 & 30.83 & 10.28 & 96.86 \\
& 6 & 16 & 29.44 & 23.89 & 5.97 & 77.22 \\
& 7 & 12 & 27.86 & 18.70 & 5.40 & 65.26 \\
\hline
\end{tabular}

${ }^{1}$ S.D., standard deviation.

${ }^{2}$ S.E., standard error.

mean, S.D. and 2 S.D. cutoff of AFP blood concentrations were determined in babies weighing $51 / 2-61 / 2 \mathrm{lb}$, and in premature infants $\left(<5 \frac{1}{2} \mathrm{lb}\right)$. From these values, it can be observed that the postnatal synthetic surge of AFP described above was also present in babies weighing $5 \frac{1}{2}-6 \frac{1}{2} \mathrm{lb}$ and in all infants considered premature by weight. In fact, the postsynthetic surge displayed in premature infants was actually extended longer in duration and appeared to plateau (3-5 days). In summary, a synthetic surge of AFP was found to occur in the first wk of life in all babies weighing less than $6 \frac{1}{2} \mathrm{lb}$ including premature infants (by weight).

Relationship of sex to AFP concentration. In 119 samples from newborn males, the mean serum AFP concentration was $22.9 \mathrm{mg} /$ liter (S.D. $=19.22$ ). In comparison, the AFP level for 107 samples 
from newborn females averaged $21.5 \mathrm{mg} /$ liter (S.D. $=18.57$ ). It was apparent that sex did not influence the serum levels of AFP in newborns. Additionally when body weight was considered, no differences regarding sex were disconcernable among the babies in the three birthweight groups (Table 3).

AFP measurement in infants older than 7 days. AFP blood determinations were made from specimens ranging in age from $1-$ 30 days (postnatal). As shown in Fig. 2, AFP levels decline rapidly after the first wk of life. Serum AFP decreases rapidly with an overall apparent half-life of 6.6 days (slope $=-0.0457$ ) by the end of the first month. Thereafter, AFP levels in the blood continue their decline to the 8th month after birth as previously described (7) wherein values are closely approximating adult AFP blood concentrations (1.0-20.0 $\mu \mathrm{g} /$ liter).

When data are partitioned according to the three birthweight groups described above, the following results were obtained (see Table 4). The half-life of AFP in the low birthweight babies was found to be 7.7 days whereas those for the infants in the middleand high birthweight categories were 5.7 days and 5.5 days, respectively. These data further indicate that differences in postnatal AFP synthesis and/or degradation exist in babies of three selected weight categories, especially the low birthweight groups.

\section{DISCUSSION}

From the results of the studies employing dried blood specimens from newborns, a number of observations can be made. First, the level of AFP (20 mg/liter) found for the medium birthweight babies during the first wk of life agrees with previous reports employing liquid blood samples $(25,36,41)$. As a result, the AFP

Table 3. Comparison of alpha-fetoprotein (AFP) serum levels in $3-$ 4-day-old male and female newborns partitioned by body weight

\begin{tabular}{|c|c|c|c|c|c|c|}
\hline & \multicolumn{6}{|c|}{ Alpha-fetoprotein (mg/liter) } \\
\hline & \multicolumn{2}{|c|}{ Low: $6 \mathrm{lb} 8 \mathrm{oz}$} & \multicolumn{2}{|c|}{$\begin{array}{c}\text { Medium: } 6 \mathrm{lb} 8 \\
\text { oz-8 } \mathrm{lb} 8 \mathrm{oz}\end{array}$} & \multicolumn{2}{|c|}{ High: $8 \mathrm{lb} 8 \mathrm{oz}$} \\
\hline & Male & Female & Male & Female & Male & Female \\
\hline Sample Size $(N)$ & 23 & 37 & 50 & 50 & 38 & 20 \\
\hline Mean & 37.07 & 33.14 & 23.40 & 19.81 & 15.80 & 17.22 \\
\hline S.D. & 27.28 & 26.35 & 16.09 & 12.97 & 15.45 & 12.65 \\
\hline S.E. & 5.68 & 4.33 & 2.28 & 1.83 & 2.51 & 2.83 \\
\hline
\end{tabular}

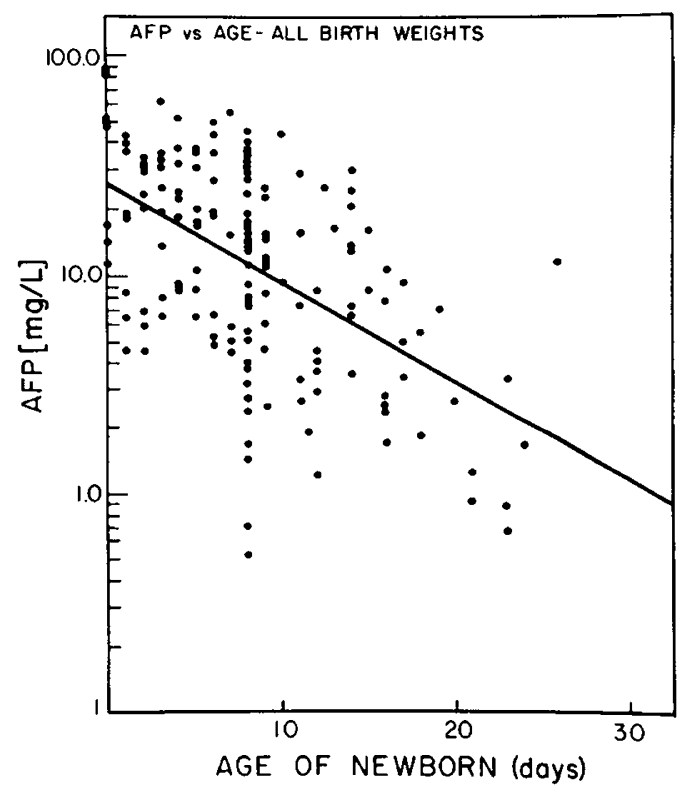

Fig. 2. Alpha-fetoprotein (AFP) blood concentrations were assayed in infant specimens ranging 1-30 days of life. The apparent half-life of AFP in babies of all birthweights was 6.6 days by the end of the first month. data, which consider birthweight where 2 S.D. cutoff points have been determined, may be helpful in determining clinical significance in various instances of perinatal disorders. Second, the sex of the infant appeared to have no influence on AFP serum concentrations in direct confirmation of prior reports $(3,14)$. Third, to our knowledge the finding of a synthetic surge in plasma AFP at day 3 for the low birthweight babies only is a new, and perhaps very significant observation. Clearly, because of the AFP values in low birthweight babies, birthweight should be included in all case histories of newborn babies undergoing AFP blood determinations. Fourth, these data in agreement with previous studies $(7,22)$ indicated that AFP blood levels decrease during the first month of life, and continually decline thereafter until adult levels are attained at eight months of age. Fifth, the half-life of AFP was found to differ among the three groups of infants subdivided by birthweight. Thus, the postnatal serum AFP levels are age-dependent and gradually decline as the infant matures.

The influence of birthweight on the blood values of AFP during the first wk of life was dramatic. It is likely that this is a reflection of gestational age because this latter parameter is well correlated with AFP blood levels $(r=-0.82)$ during development (17). In fact, AFP concentrations in cord serum have been suggested as a parameter to measure gestational age (25); however, estimation of gestational age without sonography can be highly subjective and inaccurate whereas birthweight is a discrete quantitative measurement. Furthermore, birthweight itself has been correlated with gestational age $(r=-0.77)$ (17). AFP blood levels during development and in cord blood also show correlations with birthweight ( $r=-.065$ and -0.61 , respectively) but are less marked than with gestational age $(17,25)$. We conclude that birthweight may serve as the ideal parameter upon which to measure AFP until gestational age can be established. Studies are currently in progress to relate gestational age and other perinatal parameters to our present findings.

It should be emphasized that the babies in the low birthweight category included both premature babies and those on the lownormal side of our arbitrary weight classification. The synthetic surge was found to be present in the $5 \frac{1}{2}-61 / 2 \mathrm{lb}$-category as well as in the premature babies less than $5 \frac{1}{2} \mathrm{lb}$. It is tempting to speculate that this phenomenon could be a reflection of liver immaturity and metabolism related to jaundice. Because human AFP is known to bind to bilirubin (2), the synthetic surge of AFP may be a physiologic response to high serum bilirubin levels. Bilirubin levels are already known to correlate with AFP concentrations in cord blood (20), in maternal serum and in amniotic fluid (11). The synthetic surge in low birthweight babies even appear to mimic the classical bilirubin serum curve, which has been previously described (8). Interestingly, the neonatal maturation of the glucuronyl transferase enzyme system (for bilirubin metabolism) in the liver cells normally occurs by the third day of life, but takes longer in premature infants (15). These intriguing relationships are currently under consideration in our laboratory.

Table 4. Calculation of apparent half-life of alpha-fetoprotein (AFP) in infants 1-30 days of age partitioned by birth weight

\begin{tabular}{lccc}
\hline & \multicolumn{3}{c}{ Infants, $1-30$ days old } \\
\cline { 2 - 4 } & $<6 \frac{1}{2} \mathrm{lb}$ & $6 \frac{1}{2}-8^{1 / 2} \mathrm{lb}$ & $>8 \frac{\mathrm{b}}{1} \mathrm{lb}$ \\
\hline$N$ & 98 & 125 & 90 \\
Mean age & 6.18 & 6.65 & 5.12 \\
S.D. age ${ }^{2}$ & 5.65 & 4.78 & 4.47 \\
[AFP] $^{3}$ & 20.30 & 12.85 & 12.19 \\
S.D. [AFP] & 2.73 & 2.71 & 2.78 \\
Y intercept & 35.32 & 29.05 & 23.36 \\
Slope & -0.0389 & -0.0533 & -0.0551 \\
1/2 (days) & 7.74 & 5.65 & 5.46 \\
\hline
\end{tabular}

${ }^{1} \mathrm{~N}$, number of samples.

${ }^{2}$ S.D., standard deviation.

${ }^{3}$ [AFP], mean concentration of AFP in $\mathrm{mg} /$ liter. 
Although it was initially believed that synthesis of AFP did not occur after birth, it is now well documented that AFP is continuously synthesized in small amounts after parturition $(4,16)$. Because the decrease in the postnatal AFP concentration was exponential, it was thought that the synthesis of AFP also decreased exponentially. Studies of the endogenous clearance rate and synthesis of AFP during and after blood exchange transfusions have demonstrated that residual synthetic activity does exist postnatally (4). A surge of postnatal AFP synthetic activity was presently observed as a reflection of blood levels in the low birthweight babies. Currently, we have no data to rule out cell turnover and release or secondary events leading to increased levels of AFP; however, our findings are noteworthy in that comparable activity in the medium and high birthweight categories was less striking. In fact, AFP levels in high birthweight babies tended to decline at a greater rate than that in medium birthweight babies and which in turn, displayed a steeper slope than that in low birthweight babies. These observations appear to be in confirmation of prior studies of AFP measurement in infant blood extending to $26 \mathrm{wk}$ of age (7) and also in determination of AFP half-life $(4,21)$.

It is also of great interest that high levels of maternal serum AFP detected during prenatal screening have been correlated to low birthweight babies as observed in follow-up studies $(5,38)$. Our present findings should prompt further studies in which the postnatal synthetic surge of AFP would be examined in the offspring of mothers displaying high second trimester AFP blood levels.

It is apparent that many previous studies regarding the relationship of AFP to perinatal disorders in the newborn should now be reconsidered. We suggest that studies relating AFP newborn blood concentrations to liver distress, hepatobiliary disease, and jaundice-related hemolytic disorders should be reexamined in light of age and birth weight parameters. Our presently reported AFP blood concentration cutoff points (2 S.D.) should prove helpful in this regard.

\section{REFERENCES AND NOTES}

I. Andres, J. M., Lilly, J. R., Altman, R. P., Walder, W. A., and Alpert, E.: Alpha1-fetoprotein in neonatal hepatobiliary disease. J. Pediatr., 91:217 (1977).

2. Aoyagi, Y., Ikenaka, T., and Ichida, R.: Alpha-fetoprotein as a carrier protein in plasma and its bilirubin-binding ability. Cancer Res., 39: 3571 (1979).

3. Bernal, J. E. and Wagstaff, T. I.: Cord serum AFP and the immunological status of the mother: a lack of correlation. Biol. Neonate, 37: 297 (1980).

4. Brock, D. J. H. and Sutcliffe, R. G.: Alpha-fetoprotein in the antenatal diagnosis of anencephaly and spina bifida. Lancet, 2: 197 (1972).

5. Brock, D. J. H., Barron, L., and Raab, G. M.: The potential of mid-trimester maternal plasma alpha-fetoprotein measurement in predicting infants of low birthweight. Brit. J. Obst., Gynecol., 87: 582 (1980).

6. Buffe, D.: $\alpha$-Fetoproteins and children's tumors. Gann. Monogr. Cancer Res., 14: 117 (1973)

7. Bugajer-Gleitman, H. E., Eder, G., Lachmann, D., and Pollak, A.: Erste untersuchungen uber das alpha-1-fetoprotein beim neugeborenen and fruhgeborenen. Wiener Klin. Wocenshrift., 87: 601 (1975).

8. Carswell, F., Kerr, M., and Dunsmore, L. R.: Sequential trail of effect of Phenobarbitone of preterm infants. Archiv. Dis. Childhood, 47: 62I (1972)

9. Chandra, R. K.: Alpha-fetoprotein in serum and amniotic fluid in the diagnosis of neonatal hepatitis syndrome. Indian childhood cirrhosis, cystic fibrosis, ataxia telangiectasia, and spina bifida. Indian Paed., XII: 545 (1975).

10. Chandra, R. K., MadhavanKutty, K., and Way, R. C.: Serum alpha-fetoprotein levels in patients with cystic fibrosis and their parents and siblings. Brit. Med. J., l: 7 (1975).

11. Goldstein, A. I. and Farrel, R. C.: Physiologic Jaundice of the newborn. Relation to maternal serum and amniotic fluid alpha-fetoprotein. Obst. Gynecol., 51: 315 (1978).

12. Grenier, A., Belanger, L., and Laberge, C., Alpha-1-fetoprotein measurement in blood spotted on paper: Discriminating test for hereditary tyrosinemia in neonatal mass screening. Clin. Chem., 22: 1001 (1976).

13. Grenier, A., Morissette, J., Valet, J. P., and Belanger, L.: Polystyrene tube immunoradiometric assay for human alpha-1-fetoprotein, and its use for mass screening. Clin. Chem., 24: 2158 (1978).

14. Guibaud, Bonnet, M., Thoulon, J. M., Dorche, J., and Dumont, M.: L'alpha- fetoproteine dans le sang du cordon. La Nouvelle Presse medicale, 4: 409 (1975).

15. Harris, R: The Newer hyperbilirubinemias. In: DM: Disease-a-Month, H. F Dowling, Ed. pp. 14-16 (Yearbook Med. Publ., 1968).

16. Ikonen, R. S., Lindgren, J., Niemi, E., Sorto, A. E., Seppala, M., and Ruoslahti E.: Alpha-Fetoprotein levels in neonatal hyperbilirubinaemia. Acta Paediatr. Scand., 69: 59 (1980).

17. Karlsson, B. W., Bergstrand, C. G., Ekelund, H., and Lindberg, T.: Postnatal changes of alpha-fetoprotein, albumin, and total protein in human serum. Acta Paediat. Scand., 61: 133 (1972).

18. Kubo, O., Amano, K., Tajika, and Kitamura, K.: An infant autopsy case of ependymoblastoma with high serum alpha-fetoprotein. No. Shinkei Geka., 8: $673(1980)$.

19. Leek, A. E., Ruoss, C. F., Kitau, M. J., and Chard, T.: Raised AFP in maternal serum with anencephalic pregnancy: Lancet, 2: 385 (1973).

20. Malan, C., Donald, P. R., Ondendaal, H. J., and Shanley, B.C.: alpha-1-fetoproteienin neonatale geelsug. South African Med. J., 54: 281 (1978).

21. Mann, K., Lamerz, R., Hellman, Th., Kumper, H. J., Stachler, G., and Karl, H. J.: Use of human cloronic gonadotrophin and alpha-fetoprotein radioimmunoassays: Specificity and apparent half-life determination after delivery and in patients with germ cell tumors. Oncodev. Biol. Med., I: 301 (1980).

22. Masseyeff, R., Gilli, J., Krebs, B., Calluaud, A., and Bonet, C.: Evolution of alpha-fetoprotein serum levels throughout life in humans and rats, and during pregnancy in the rat. Ann N.Y. Acad. Sci., 259: 17 (1975).

23. Milosavljevic, J., Stajic, M., and Vilhar, N.: Diagnostic significance of alphafetoproteins in neonatal hyperbilirubinaemias and primary cancer of the liver in adults. Acta Hepat. Gastroenteral., 24: 30 (1977)

24. Mizejewski, G. J., Bellisario, R., Beblowski, D. W., and Carter, T. P.: Adaptation of a Commercial RIA kit for the measurement of alpha-fetoprotein in newborn dried blood specimens. Clin. Chem., 28(5): 1207 (1982).

25. Norgaard-Pedersen, B.: Alpha-1-fetoprotein concentration in cord serum as a parameter for gestational age. Acta Paediatr. Scand., 62: 167 (1973).

26. Rebolledo, L., Gonzalez, B., and Sorensen, R.: Alfafetoproteina en Pediatria. Rev. Chilena de Ped., 47: 225 (1976).

27. Saito, S., Kaneko, M., Tsuchida, Y., Honna, T., Matsui, A., Shiraki, K., Sakurai, M., and Endo, Y.: Alpha-fetoprotein in infantile obstructive jaundice in comparison with the normal ranges. Oncodev, Biol. Med., l: 227 (1980).

28. Sehgal, S., Aikat, B. K., Bhattacharya, T., and Walia, B. N. S.: Immunological studies in Indian childhood cirrhosis. Indian J. Med. Res., 65: 89 (1977).

29. Seppala, M., and Ruoslahti, E.: Alpha-fetoprotein in Rh-immunized pregnancies. Obst. Gynecol., 42: 701 (1973).

30. Simons, M. J. and Hosking, C. S.: AFP and ataxia-telangiectasia. Lancet, 1: 1234 (1978).

31. Smith, J. A.: Serum alpha-fetoprotein in cystic fibrosis. Brit. Med. J., 2: 392 (1975).

32. Teppo, A. M. and Simell, O.: Endogenous clearance rate and synthesis of alphafetoprotein in, during, and after blood exchange transfusion in hyperbilirubinaemic newborns. Acta Paediatr., 69: 491 (1980).

33. Theodorides, C. G., Bourloyiannis, C., Papagregoriou, M., Lagos, P., and Matsaniotis, N.: Serum alpha-1-fetoprotein levels in congenital hypothyroidism. Pediatr. Res., 12: 1085 (1978)

34. Tourne, C. E., Brettes, J. P., Guez, G., Ritter, J., and Gandar, R.: Alphafoetoproteine et ictere neonatal Contribution a l'etude d'un mecanisme physiopathologique. J. Gynecol. Obst. Biol. Repr., 6: 331 (1977).

35. Tsuchida, Y.: Clinical significance of AFP levels in infant patients serum tested by radioiunoassay. Horumon to Rinsho., 26: 1071 (1978).

36. Tsuchida, Y., Kaneko, M., Saito, S., Endo, Y., Shiraki, K., and Ohmi, K.: Analysis of serum alpha-fetoprotein dynamics in early infancy. Scand. J. Immunol., 8 (Suppl. 8): 235 (1978).

37. Wald, N. J., Cuckle, H., Brock, D. J. H., Peto, R., Polani, P. E., and Woodford, F. B.: Maternal serum alpha-fetoprotein measurement in antenatal screening for anencephaly and spina bifida in early pregnancy. Report of the U. K. Colaborative study on Alpha-fetoprotein in relation to Neural Tube Defects, Lancet, 1: 1323 (1977).

38. Wald, N. J., Cukle, H. S., Borham, J., and Turnbull, A. C.: Maternal Serum alpha-fetoprotein and birthweight. Brit. J. Obst. Gynecol., 87: 860 (1980).

39. Waldmann, T. A. and Mclntire, K. R.: Serum alpha-fetoprotein levels in patients with ataxia-telangiectasia. Lancet, $2: 1112$ (1972).

40. Waldman, T. A. and McIntire, K. R.: The use of radioimmunoassay for alphafetoprotein in the diagnosis of malignancy. Cancer, 34: 1510 (19).

41. Wu, J. T., Book, L., and Sudar, K.: Serum alpha Fetoprotein (AFP) levels in normal infants. Pediatr. Res., 15: 50 (1981).

42. Zeltzer, P. M.: Alpha-fetoprotein in the differentiation of neonatal hepatitis and biliary atresia: Current status and implications for the pathogenesis of these disorders. J. Pediatr. Surg., 13: 381 (1978).

43. Requests for reprints should be addressed to: Dr. Gerald J. Mizejewski, Birth Defects Institute, Center for Laboratories and Research, New York State Health Department, Empire State Plaza, Albany, NY 12201.

44. Received for publication January 8,1982

45. Accepted for publication May 6, 1982. 